Relations industrielles

Industrial Relations

\title{
Why Democracy?
}

\section{Paul Martin}

Volume 1, numéro 1, septembre 1945

URI : https://id.erudit.org/iderudit/1023892ar

DOI : https://doi.org/10.7202/1023892ar

Aller au sommaire du numéro

\section{Éditeur(s)}

Département des relations industrielles de l’Université Laval

\section{ISSN}

0034-379X (imprimé)

1703-8138 (numérique)

Découvrir la revue

\section{Citer cet article}

Martin, P. (1945). Why Democracy? Relations industrielles / Industrial Relations, 1(1), 4-4. https://doi.org/10.7202/1023892ar

Tous droits réservés @ Département des relations industrielles de l’Université Laval, 1945
Ce document est protégé par la loi sur le droit d'auteur. L’utilisation des services d'Érudit (y compris la reproduction) est assujettie à sa politique d'utilisation que vous pouvez consulter en ligne.

https://apropos.erudit.org/fr/usagers/politique-dutilisation/ 


\section{LA COMMISSION DE RELATIONS OUVRIÊRES DE LA PROVINCE DE QUÉBEC}

Le 3 février 1944, l'Assemblée législative adoptait la Loi des relations ouvrières concernant les négociations collectives et l'arbitrage obligatoires. Quinze jours plus tard, le Cabinet fédéral édictait C.P. 1003. On sait que le principe des négociations collectives obligatoires contraint les employeurs à négocier une entente avec les représentants des associations ouvrières certifiées à cette fin lorsqu'elles groupent la majorité des travailleurs. Le principe des négociations collectives obligatoires implique la réglementation du droit de grève. Les ouvriers ne peuvent déclarer la grève sans recourir d'abord a la conciliation et à l'arbitrage. Le droit de grève existe toujours, mais il est rigoureusement réglementé.

Cette loi s'imposait. Pour s'en convaincre, il suffit de considérer certaines statistiques de la Commission de Relations ouvrières de notre province. Du 3 février 1944 au 31 mars 1945, la Commission a enregistré 1,153 demandes de certification des syndicats ouvriers couvrant 79,590 travailleurs. - Si l'on tient compte du fait que les industries de guerre relevaient de C.P. 1003, on a une idée des progrès accomplis par le syndicalisme au point de vue de l'organisation. L'absence de la Commission de Relations ouvrières aurait provoqué un nombre formidable de conflits. Grâce au principe des négociations collectives obligatoires, nous sommes dans la bonne voie, celle de la collaboration entre les employeurs et les associations ouvrières.

\section{WHY DEMOCRACY?}

( Labour believes that human values are best realized by use of the democratic tool : by patience, forbearance, and by the practical compromise.

(This democratic tool has four functions: political, civil, economic, and ethical. They are related, yet each is distinct in its purpose.

( Political democracy insures the right to vote, to hold office, to form a political party, to criticize the government.

( Civil democracy guarantees individual liberty, and leave tolive by no man's leave, in equality under the law.

« Economic democracy first insures the minimum social and economic requirements of all, and then provides equality of opportunity to develop capacities to the full. It means freedom from rigidity of status, economy in the use of human resources - putting things where they will do the most good. The organization and coordination, the effective planning and administration, necessary to make the full use of all resources, material and human, is the purpose of economic science.

(I Ethical democracy is virtually the ethics of Christianity respect for the individual and the equality of all before God.

" The democratic tool is not effective where there is agreement about the fundamentals of society, about the end-value - whether, for instance, it is more important to sustain private power or promote social welfare 》).

(Labour's Post-War World

$$
\text { Hon. Paul M arten, K.c., M.P. }
$$

Behind the Headlines, vol. $5, n^{\circ} 1$, p. 3).

\section{LES COMITÉS MIXTES DE PRODUCTION}

A l'exemple des Etats-Unis et de la Grande-Bretagne, le Canada a favorisé l'institution de comités mixtes de production au cours de la guerre en vue d'accroftre le rendement des usines et développer le sens de l'initiative et de la responsabilité chez les travailleurs. Les employeurs et les syndicats ouvriers ont apporté toute leur collaboration au gouvernement fédéral qui a patronné le mouvement. Le Financial Post du 18 aout rapporte qu'une compagnie ontarienne admet avoir augmenté sa production dans une proportion de $17 \%$ grâce à l'institution d'un comité mixte de production.

Au mois de mars dernier on comptait 315 comités englobant 286,935 travailleurs. C'est l'intention d'Ottawa, en collaboration avec les provinces, de maintenir les comités mixtes de production et d'en accrottre le nombre dans les industries de paix. C'est une décision sage. A condition que ces comités n'empiètent en rien sur le domaine des conventions collectives (salaires, heures de travail règlement des griefs, etc.), ils permettent aux travailleurs d'apporter leur concours a la solution des problèmes de production.

\section{LE CONGRES MONDIAL DES SYNDICATS OUVRIERS}

Le 25 septembre débutera, à Paris, une importante conférence internationale pour les travailleurs. C'est la suite du Congrès de Londres de février qui réunissait les représentants de soixante millions de travailleurs appartenant a $\mathbf{4 0}$ pays. - Il semble que l'Internationale syndicale d'Amsterdam s'évanouira pour laisser le champ libre à un nouvel organisme qui comprendra notamment les syndicats soviétiques et le C.I.O. La Fédération américaine du Travail a refusé de joindre les rangs du nouvel organisme, tandis que les travailleurs canadiens y participeront.

Une Fédération internationale syndicale est nécessaire. Un vaste champ de collaboration s'impose aux syndicats sur le plan international. L'objectif principal du prochain Congrès est d'obtenir que le nouvel organisme international syndical ait un lien direct avec le Conseil économique et social prévu dans la Charte des NationsUnies. Sans porter un jugement définitif sur cet objectif, il y a lieu de se demander si les syndicats ne commettraient pas une erreur en empiétant sur le domaine réservé jusqu'ici à l'Organisation internationale du Travail. Grâce a l'O.I.T. les syndicats ont acquis un pouvoir quasi législatif qui a donné des résultats appréciables. On pourrait regretter d'avoir saisi l'ombre au lieu de la réalité. On prévoit que plusieurs leaders syndicalistes de grande réputation empécheront les travailleurs de commettre pareille erreur. La constitution de l'O.I.T. sera amendée. Aux syndicats d'en profiter pour doter l'O.I.T. d'un mécanisme plus efficace, si l'on n'est pas satisfait de ce qui a été accompli à date. L'O.I.T. et une Fédération internationale syndicale ont chacune leur domaine d'action propre. Loin de s'opposer, elles se complètent mutuellement. 